\title{
INFLUENCE OF TEMPERATURE ON A FALLING FILM INSTABILITY
}

\author{
Džana Kadrić, Berina Delalić \& Mirela Alispahić
}
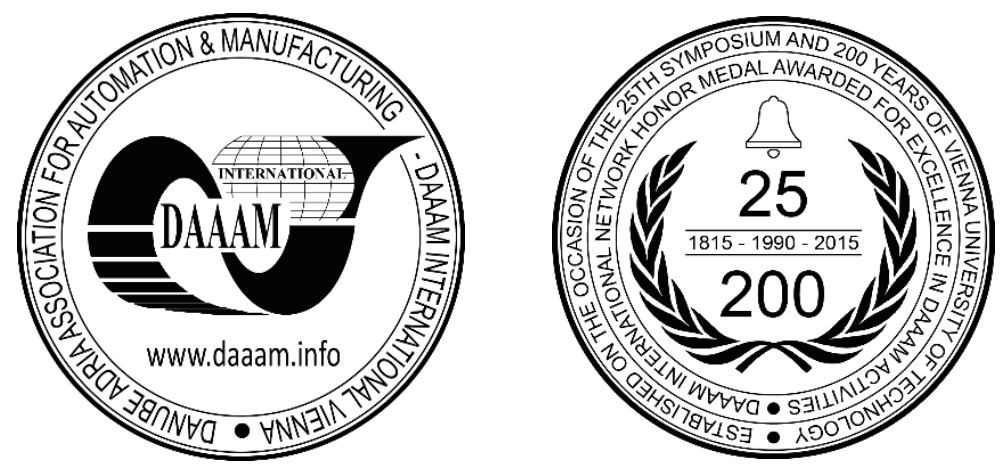

This Publication has to be referred as: Kadric, D[zana]; Delalic, B[erina] \& Alispahic, M[irela] (2016). Influence of Temperature on a Falling Film Instability, Proceedings of the 27th DAAAM International Symposium, pp.0261-0265, B. Katalinic (Ed.), Published by DAAAM International, ISBN 978-3-902734-08-2, ISSN 1726-9679, Vienna, Austria DOI: $10.2507 / 27$ th.daaam.proceedings.038

\begin{abstract}
Results of experimental research of influence of a film temperature on a falling film brake-up are shown for case of the continuous film brake-up and wetting of the previously dry plate, which represents very important regimes for heat transfer equipment such as some models of heat exchangers. Experiments are conducted on a vertical plate and distilled water as a working fluid. For case of the brake-up of the continuous falling film, which was observed for Reynolds numbers smaller than 1 , and inlet liquid film temperature has no influence on the minimum wetting rate. During the facility start-up high flow rates are needed to completely cover the plates. This regime was investigated for elevated film temperature and two material surface treatments. It is shown that sandblasted plates provide better ratio of wetted width than polished plates, with smaller advancing contact angles while rivulets hydrodynamics was driven by the higher surface tension forces.
\end{abstract}

Keywords: experimental work; heat transfer equipment; film temperature; film instability.

\section{Introduction}

Thin, falling liquid films are encountered in many industrial applications (e.g. distillation facilities, cooling towers, vertical tube evaporators, falling film chemical reactors, food processing facilities, etc.), due to their high efficiency in heat and mass transfer. Three different cases are recognized as critical conditions; wetting of the previously dry plate during the facility start-up, break-up of the continuous liquid film and rewetting of plate after a short stop. Liquid-flow rate that corresponds to these regimes is called a minimum wetting rate and the corresponding film thickness is called a minimum film thickness [1]. Theoretical models derived for prediction of the minimum wetting rate and corresponding film thickness are mostly based on two criteria: the force balance in the stagnation point and the minimum total energy of rivulets [1-5]. Hysteresis of minimum wetting rate and minimum film thickness for three regimes is recorded and experimentally confirmed [6], [7]. Influence of contact angle (receding, advancing and equilibrium) on the minimum wetting rate is confirmed as well as the influence of the plate inclination angle [7]. Many researchers have shown that increase of fluid temperature results in a decrease of the minimum wetting rate [6], [8]. This was studied experimentally for combination distilled water/sandblasted copper plate for which receding contact angle is equal to zero therefore adhesion forces are very strong. Due to the strong adhesion forces, continuous falling film remain stable for very small 
Reynolds numbers, smaller than 1. Hysteresis of flow rate for wetting of the previously dry plate compared to break-up of continuous falling film is recorded, where for previous film regime the Reynolds number is approximately 150 .

\section{Experimental setup}

Experimental setup used in presented examination is illustrated in Fig. 1. Liquid line consists of liquid reservoir with temperature regulation and laboratory pump which drives the working fluid through distributor towards the target surface. The narrow stainless steel (X5CrNi 18-10) plate was placed vertically onto support. The plate dimensions are $500 \times 100$ with wetted length of $410 \mathrm{~mm}$. Average roughness of stainless steel plate is $R_{a}=1,15 \mu \mathrm{m}\left(R_{z}=2,04 \mu \mathrm{m}\right)$, while sandblasted plate had resulting average roughness of $R_{a}=1,3 \mu \mathrm{m}\left(R_{z}=11,3 \mu \mathrm{m}\right)$. During the experiment, liquid temperature was ranged from $20^{\circ} \mathrm{C}$ to $52^{\circ} \mathrm{C}$, while surrounding temperature was $19^{\circ} \mathrm{C}$.

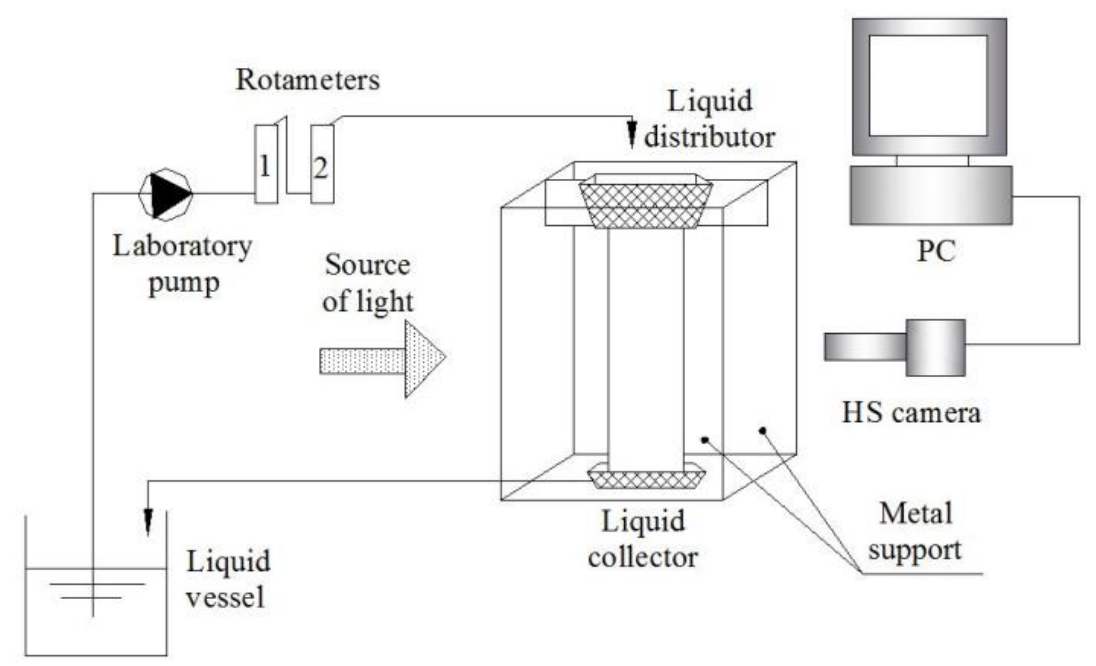

Fig. 1. Experimental setup

\section{Experimental results}

Two sets of experiments were carried out: measurement of brake-up for various inlet liquid temperature on the sandblasted vertical plate and measurements of wetting of the previously dry plate for various liquid temperature performed on the sandblasted and on a polished plate, both from stainless steel. Contact angle for tested liquid and plate are recorded, following the general experimental procedure given in detail in [7].

\subsection{Brake-up of the continuous liquid film}

Experiments performed on isothermal liquid film and sandblasted surface showed that continuous liquid film remains stable even for very small liquid flow rates, with equivalent Reynolds numbers lower than 1 and fluid velocity at the entrance zone lower than $0,002 \mathrm{~m} / \mathrm{s}$.

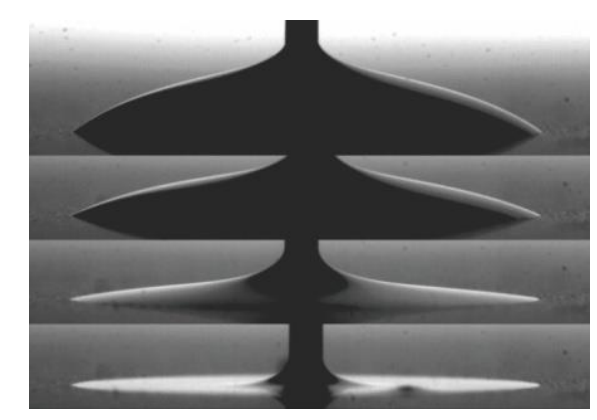

Fig. 2a. Receding contact angle between liquid and plate
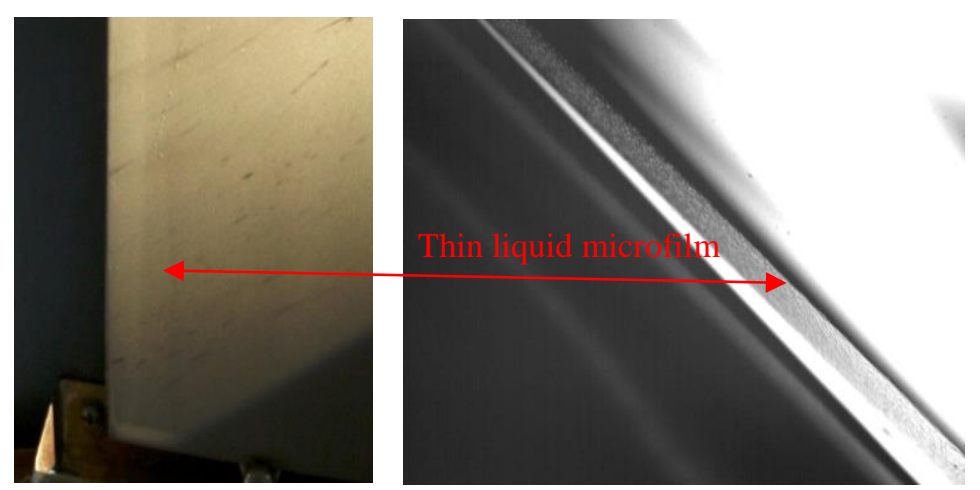

Fig. 2b. Microfilm formed on the plate for $\mathrm{Re}=0,4$ (photograph and laboratory camera view) 
Adhesive forces between liquid and plate material are very strong, which is indicated by zero receding contact angle, as shown in Fig. 2a. Very thin layer of microfilm is observed while liquid flow rate decreases, which also confirms that high adhesive forces are presented (Fig. 2b.).

Due to the very small flow rates, the increase of liquid temperature shows no impact on the film brake-up, even for conditions with temperature of liquidup to $50^{\circ} \mathrm{C}$, which was significantly higher than the ambience temperature.

Thermography has proven to be useful tool for various engineering applications [9], [10] so it has been used during the measurement in order to show liquid temperature in a qualitatively manner. In order to obtain exact temperature field some parameters must be precisely known (such as emissivity and temperature of ambient) however, thermographic images provide useful information. In Fig.3. temperature field of liquid film is shown for inlet liquid temperature of 29 ${ }^{\circ} \mathrm{C}$ for two liquid flow rates. It is noticeable how temperature of the liquid film decrease as the flow rate decreases, for flow rates higher than brake-up flow rates. Since minimum wetting flow rate was approximately $0,02 \mathrm{l} / \mathrm{m} \cdot \mathrm{min}$, (wetted perimeter equals to the plate width), temperature of the film decreases and process parameters became like in the isothermal process. This was recorded for every tested temperature.

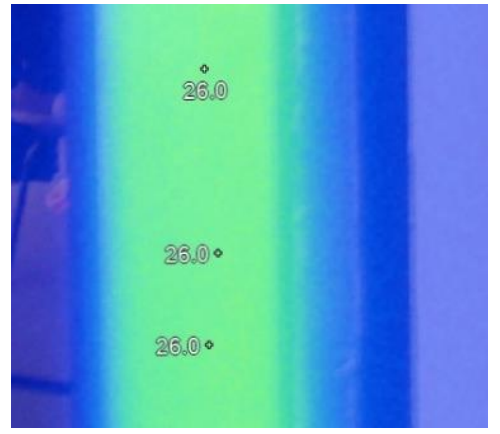

a) flow rate $2,67 \mathrm{l} / \mathrm{m} \cdot \min$

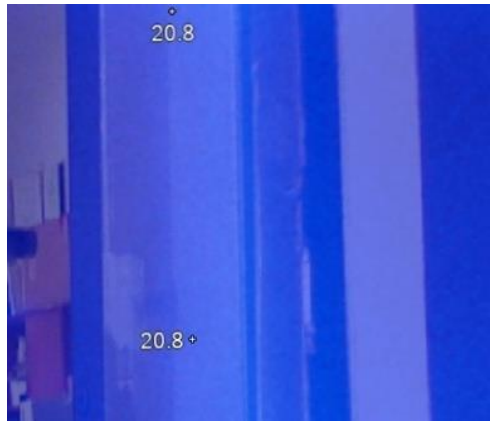

b) flow rate $0,2 \mathrm{l} / \mathrm{m} \cdot \mathrm{min}$

Fig. 3. Temperature field of liquid film for decrease of flow rate (liquid temperature of $29^{\circ} \mathrm{C}$ )

\subsection{Wetting of the previously dry plate}

Hysteresis of flow rates has been confirmed experimentally [7], according to which the flow rates necessary to form a continuous liquid film on the previously dry plate are significantly higher that flow rates detected when continuous film brakes-up.
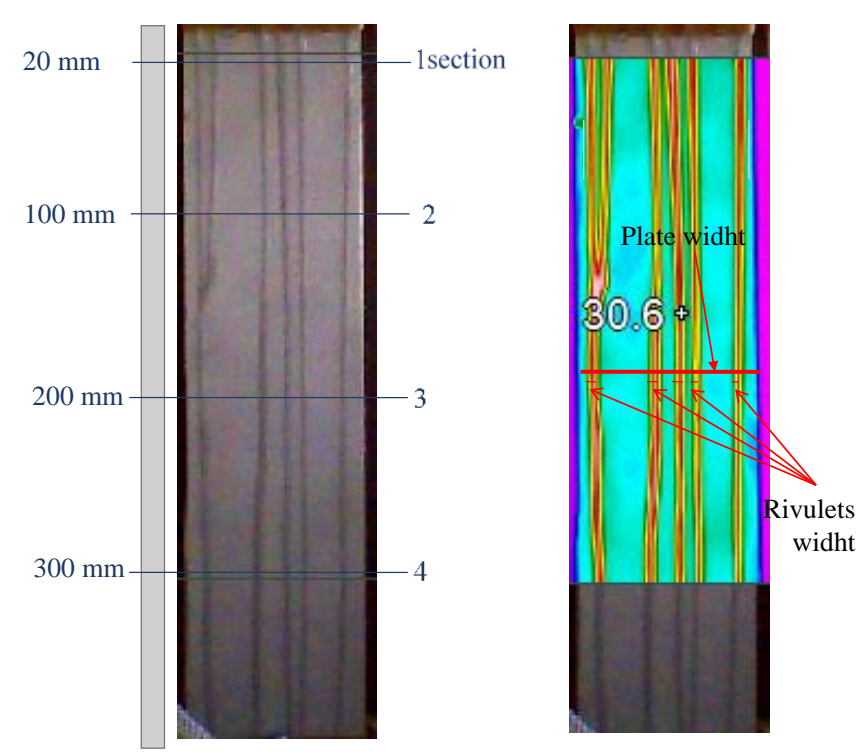

Fig. 4. Liquid rivulets recorded for liquid flow rate 0,24 1/min

Contact angle is in correlation with the minimum wetting rate as follows: a receding contact angle for the breakup of a continuous liquid film and advancing contact angle for wetting of a previously dry surface. Measured advancing contact angle for distilled water and sandblasted stainless steel has value of $75,5^{\circ}$, which is significantly higher than receding contact angle. Minimum flow rate needed to form a continuous liquid film on a dry plate is in average $11 / \mathrm{min}$ in case of isothermal film. 
For tested temperatures, resulting flow rate was the same as for the isothermal film, but flow hydrodynamics was in some aspects different. This was shown through parameter called ,,ratio of wetted width" determined for several sections along the plate, as shown in Fig. 4. Ratio of wetted width presets ratio of rivulets width to plate width (total wetted width).

Dependence of the parameter ratio of wetted surface on volume flow rate is shown in Fig. 5. for two different cases of liquid inlet temperatures and flow rates ranging from $0,151 / \mathrm{min}$ to $1 \mathrm{l} / \mathrm{min}$. It is noticeable that, for lower volume flow rate, the ratio of wetted width is similar for both cases of inlet temperature and it increases while volume flow rate increases. For colder fluid it increases gradually, while for higher liquid temperature it increases steeply. Ratio of wetted width increases gradually since kinetic energy force dominates over the surface forces, until a dry patch disappears. For heated liquid flow, the rivulets are thin and they are getting cooled in direct contact with cold plate. Therefore, the wetting mechanism is similar as in case of cold fluid. As volume flow rate increases, average rivulets and film temperature also increases therefore surface tension forces decreases. Meanwhile, kinetic energy of rivulets increases since volume flow rate increase which all together results in a sudden increase of ratio of wetted width. After that the force balance again and establishes a somewhat milder trend of ratio of wetted width as volume flow rate increases, until the final formation of the front liquid film.

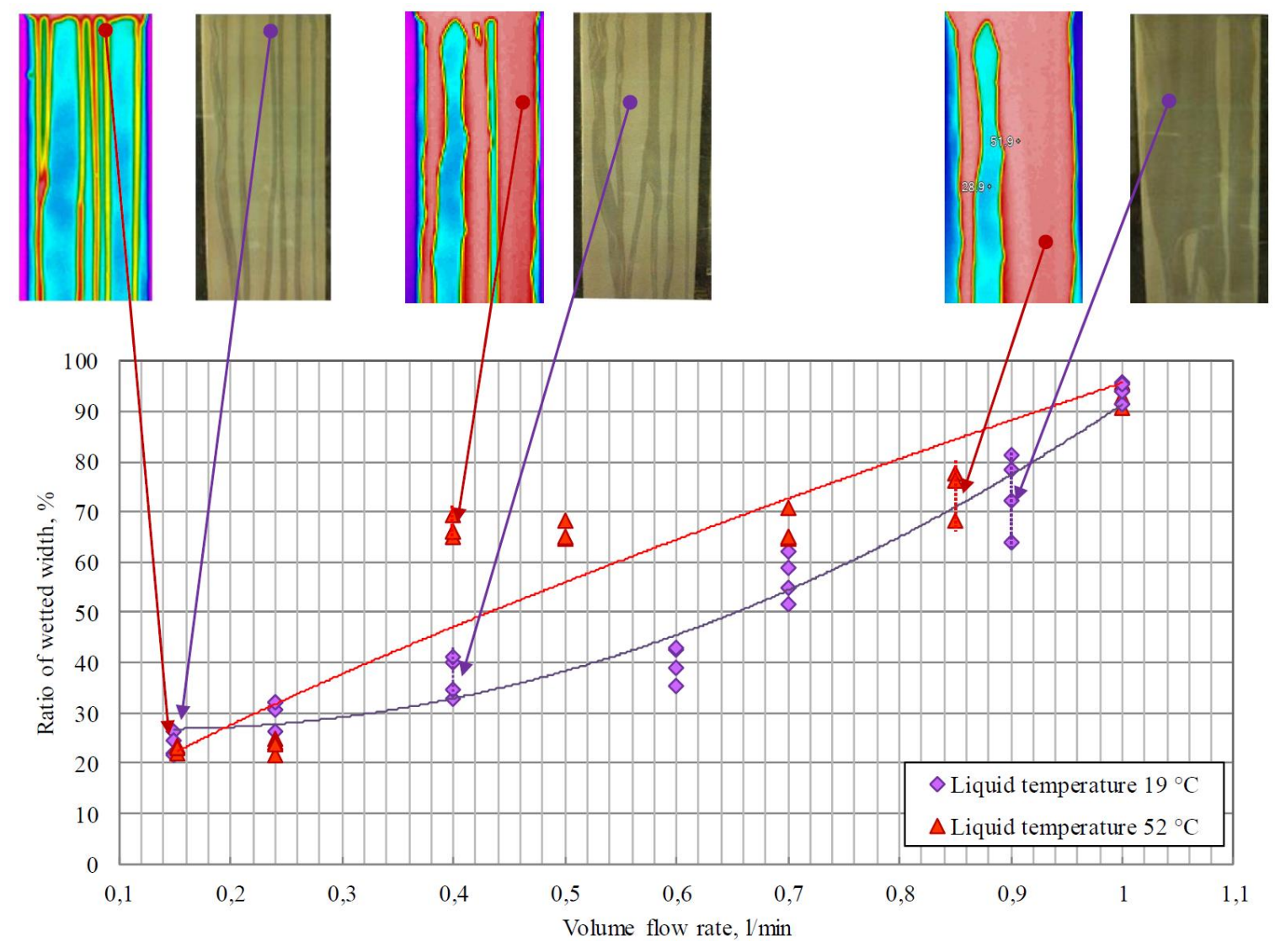

Fig. 5. Ratio of wetted width as a function of volume flow rate for two cases of liquid temperature

\subsection{Wetting of the previously dry plate with different surface treatment}

In order to test an influence of the surface treatment on a formation of the continuous liquid film, wetting of dry stainless steel plate subjected to the sandblasting and to the polishing is recorded. Liquid temperature was $52^{\circ} \mathrm{C}$. Starting liquid flow rate was $0,15 \mathrm{l} / \mathrm{min}$ and is was gradually increased up to $1 \mathrm{l} / \mathrm{min}$.

Values of the ratio of the wetted width for various liquid flow rates are shown in Fig. 6.

Comparison of ratio of wetted width for two cases of surface treatment shows that sandblasted surface presents surface with higher wetting potential. For polished surface, even for higher liquid flow rate, ratio of wetted width slightly increases. This means that thickness and velocity of rivulets increases while liquid flow rate increases but ratio of wetted width remains smaller than $50 \%$ in average.

For smaller flow rates, meandering rivulets are formed and they merge into a narrow liquid front. For sandblasted surface, rivulets flow in parallel and gradually combine as flow rate increases. Plate roughness is smaller for polished surface, which explains difference in minimum wetting flow rates. Also, even after a detail cleaning of the polished surface, it is reasonable to conclude that remains of polishing pasta are present on a plate surface, which results in a hydrophobic surface. 
Advancing contact angle for polished surface is $80^{\circ}$, which is higher than for the sandblasted surface. All these facts are working in favor with the recorded results.

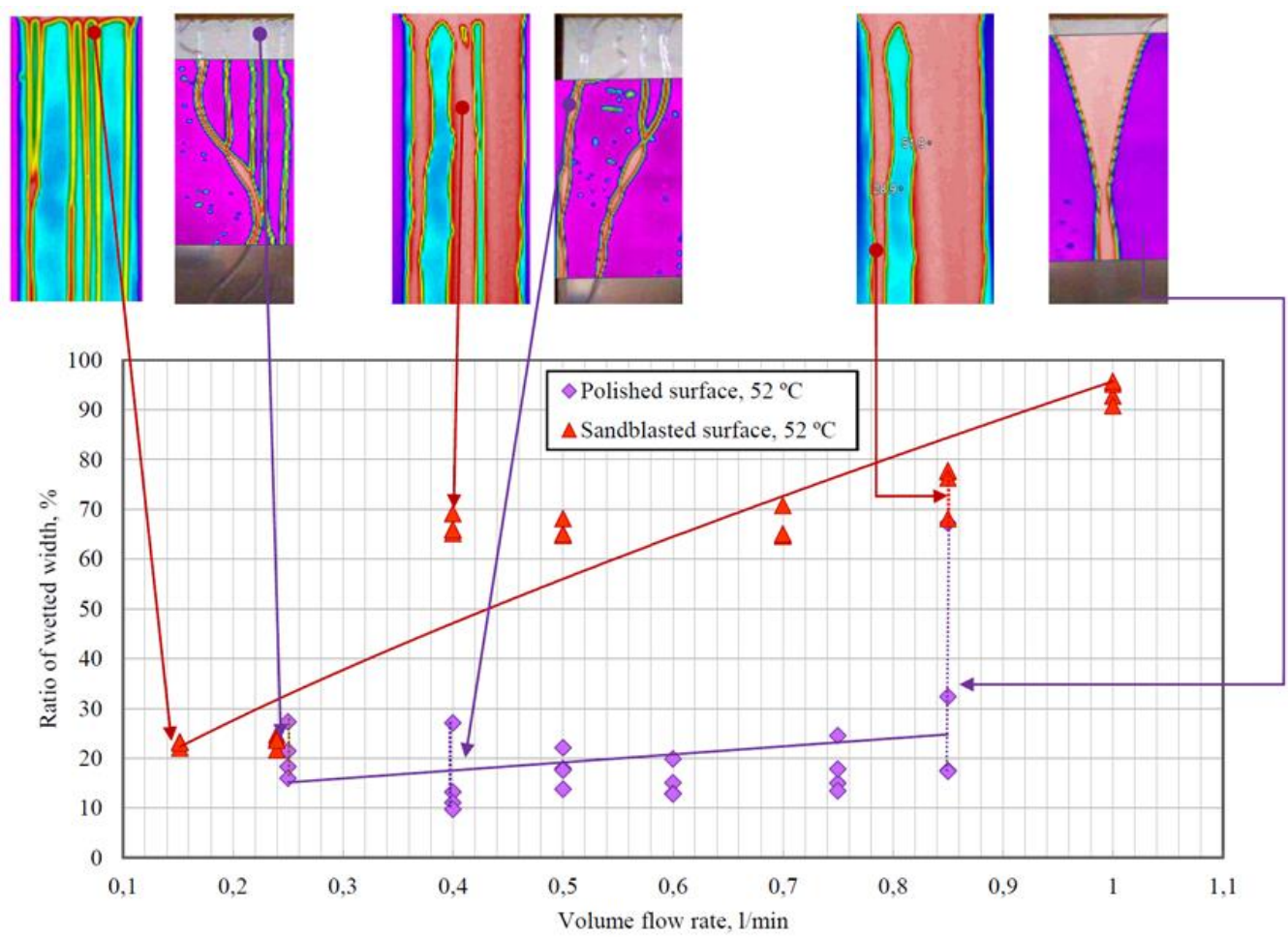

Fig. 6. Ratio of wetted width as a function of volume flow rate for two cases of surface treatment

\section{Conclusion}

Results of experiments conducted on a vertical plate and distilled water as a working fluid for the case of the brake-up of the continuous falling film, observed in region of Reynolds numbers smaller than 1 , showed that liquid film temperature has no influence on the minimum wetting rate. It is shown that sandblasted plates provide better ratio of wetted width than polished plates, with smaller advancing contact angles while rivulets hydrodynamics was driven by the higher surface tension forces. Elevated liquid temperature has no effect on minimum wetting rate on the previously dry surface, but experimental results reveals how process is driven by the balance of the surface tension forces and kinetic energy forces.

\section{References}

[1] M.S. El-Genk and H.H. Saber(2001).Minimum thickness of a flowing down on a vertical surface, Int. J. Heat Mass Transfer, 44:2809-2825

[2] D.E. Hartely, W. Murgatroyd(1964). Criteria for the break-up of thin liquid layers flowing isothermally over solid surface, Int. J. Heat Mass Transfer, 7: 1003-1015

[3] T. Hobler (1964). Minimum surface wetting, Chem. Stosow, 2B:145-159

[4] S.G. Bankof (1971). Minimum thickness of a draining liquid film, Int. J. Heat Mass Transfer, 14:2143-2146

[5] J.Mikielewicz and J.R. Moszynski(1976). Minimum thickness of a liquid film flowing vertically down a solid surface, Int. J. Heat Mass Transfer, 19:771-776

[6] D. Moalem-Maron, N. Brauner (1983). Transport characteristics of wavy thin films on inclined surfaces, Advance in Two-Phase flow and Heat Transfer, Vol. 1:155-181

[7] Džana, Kadrić; Mirela, Alispahić; Šefko, Šikalo; Suad, Jakirlić and Ejup N. Ganić (2015), Proceedings of the Eight International Symposium on Turbulence, Heat and Mass Transfer, K. Hanjalić, T. Miyauchi, D. Borello, M. Hadžiabdić, P. Venturini (Editors), Begell House, Inc. New York, Wallingford (UK). ISBN 2377-2816 (Online); ISBN 2377-4169 (CD-ROM); Extended abstract p. 221-224

[8] Moalem-Maron, D. and Brauner, N. (1983). Transport characteristics of wavy thin films on inclined surfaces, Advance in Two-Phase flow and Heat Transfer, Vol. 1, 155-181

[9] Stefan, Franko; Eva, Babusova; Miroslav, Badida; (2011). Annals of DAAAM for 2011 \& Proceedings of the 22nd International DAAAM Symposium, ISSN 1726-9679 ISBN 978-3-901509-83-4, Editor B. Katalinic, Published by DAAAM International, Vienna, Austria, Volume 22, No. 1, 1233-1234

[10] Džana, Kadrić; (2011). Annals of DAAAM for 2011 \& Proceedings of the 22nd International DAAAM Symposium, ISSN 1726-9679 ISBN 978-3-901509-83-4, Editor B. Katalinic, Published by DAAAM International, Vienna, Austria, Volume 22, No. 1, 1063-1065 